\title{
KARAKTERISTIK BATANG PENTANAHAN SISTEM ARANG-GARAM (SIGARANG) SEBAGAI UPAYA PERBAIKAN SISTEM PENTANAHAN
}

\author{
Zainal Abidin \\ Program Studi Teknik Elektro Universitas Islam Lamongan \\ E-mail: ina19474@gmail.com
}

\begin{abstract}
The research was conducted in Lamongan regency in the south of Sarirejo Village and Mantup Subdistrict of Lamongan Regency, which is a sample of most of the soil conditions in the area which is dry with an average water depth of $100 \mathrm{~m}$, so in the case of electric ground becomes less ideal. According to PUIL 2000 that the grounding on the infiltration of the recommended house at least $5 \Omega$ and a maximum of $10 \Omega$. The use of a charcoal system grounding model (SIGARANG) becomes an earthing alternative that can be used for earthing household installation systems. Based on the result of the research, it is concluded that ground water, salt and charcoal with the size of 5: 2: 1 yields an average resistivity value of $1.52 \Omega$ on soil of wet soil conditions in Table 4.1, and an average of $2.43 \Omega$ on wetland of wet conditions in Table 4.3. compared with the method without the mean of the average value on $3 \Omega$ and 3 tanah lime soils. Grounding using water, salt and char (SIGARANG) can produce $75 \%$ earthing efficiency in limestone soils. The earth earthing efficiency of the soil is $65 \%$ on average compared to groundless earth.
\end{abstract}

Keywords: Earthting system, Garang-Arang System (SIGARANG)

\section{INTISARI}

Penelitian yang dilakukan di daerah Kabupaten Lamongan sebelah selatan tepatnya di Desa Sarirejo dan Kecamatan Mantup Kabupaten Lamongan yang merupakan sampel dari kebanyakan kondisi tanah di daerah tersebut yang kering dengan kedalaman mata air rata-rata $100 \mathrm{~m}$, sehingga dalam kasus pentanahan listrik menjadi kurang ideal. Menurut PUIL 2000 bahwa pentanahan pada insatalasi rumah yang anjurkan minimal $5 \Omega$ dan maksimal $10 \Omega$. Penggunaan model pentanahan sistem garam-arang (SIGARANG) menjadi alternatif pentanahan yang dapat digunakan untuk pentanahan sistem instalasi rumah tangga.

Berdasarkan hasil penelitian disimpulkan bahwa pentanahan air, garam dan arang dengan ukuran 5:2:1 menghasilkan rata-rata nilai tahanan $1,52 \Omega$ pada tanah padas kondisi tanah basah pada tabel 4.1, dan rata-rata $2,43 \Omega$ pada tanah kapur kondisi basah pada tabel 4.3. dibandingkan dengan metode tanpa Sigarang pentanahan nilai rata- rata pada tanah padas $3 \Omega$ dan pada tanah kapur 3,5 $\Omega$. Pentanahan menggunakan air, garam dan arang (SIGARANG) dapat menghasilkan efisiensi pentanahan sebesar $75 \%$ pada tanah kapur. Efisiensi pentanahan pada tanah padas rata-rata $65 \%$ dibandingkan pentanahan tanpa SIGARANG.

Kata Kunci : Pentanahan, Sistem Garang-Arang (SIGARANG)

\section{PENDAHULUAN}

Di dalam PUIL 2000 disebutkan bahwa pada instalasi listrik ada dua jenis resiko utama yaitu: a. Arus kejut listrik, b. Suhu berlebihan yang sangat mungkin mengakibatkan kebakaran, luka bakar atau efek cedera listrik.

Harga tahanan jenis tanah pada daerah kedalaman yang terbatas tidaklah sama. Beberapa faktor yang mempengaruhi tahanan jenis tanah yaitu : a) Keadaan struktur tanah antara lain ialah struktur geologinya, seperti tanah liat, tanah rawa, tanah berbatu, tanah berpasir, tanah gambut dan sebagainya; b) Unsur kimia yang terkandung dalam tanah, seperti garam, logam, dan mineral-mineral lainnya, c). Keadaan iklim, basah atau kering, d) Temperatur tanah dan jenis tanah, e) Struktur dan karakteristik tanah merupakan salah satu faktor yang perlu diketahui karena berkaitan erat dengan hambatan jenis tanah. Kadangkala pada penanaman elektroda memungkinkan kelembaban dan temperatur bervariasi, untuk hal seperti ini nilai hambatan jenis tanah harus diambil dari keadaan yang paling buruk, yaitu tanah kering dan dingin. 
Sistem pentanahan instalasi rumah tangga di lapangan senantiasa disamakan untuk semua jenis tanah, tanpa peduli kondisi tanah itu memiliki perbedaan jenis tanah. Di daerah Mantup dan Sarirejo dengan kondisi tanah kering dimana titik air tanah memiliki kedalaman rata-rata $100 \mathrm{~m}$ akan berbeda sistem pentanahan yang harus diaplikasikan pada sistem instalasi rumah. Dengan alternatif sistem pentahanan yang dimodifikasi dengan campuran arang dan garam diharapkan akan memperbaiki sistem pentanahan instalasi rumah tangga.

\section{METODE PENELITIAN}

\section{A. Metode Sistem Grounding Arang dan Garam}

SIGARANG (Sistem Grounding Arang dan Garam) adalah suatu sisitem pentanahan menggunakan arang dan garam. Penelitian dilakukan dengan cara melakukan perhitungan terhadap data resisitivitas tanah yang telah diberikan perlakuan fisik berupa penambahan air, garam dan arang yang bertujuan untuk mencari nilai resistivitas yang rendah dari tanah tersebut. Penelitian karakteristik tanah ini dilakukan dengan penambahan air, arang dan larutan garam dan mengikuti beberapa langkah. Tanah dikeringkan dan dibuat sehomogen mungkin dengan menghaluskan tanah. Tanah ditreatment dengan menambah air atau garam atau arang dengan persentase sesuai yang diinginkan. Penelitian tanah dilakukan dengan penambahan air pada tanah kering dengan penambahan sebanyak $2,5 \%$ berat tanah atau setara 25 gram berat air.

Penambahan dilakukan secara bertahap sebanyak 2,5\% sampai dengan $15 \%$. Pencampuran tanah dan air dilakukan secara merata. Penelitian dilakukan dengan penambahan arang yang sudah dihaluskan pada tanah kering dengan penambahan sebanyak 2,5 $\%$ berat tanah atau setara 25 gram berat arang. Penambahan dilakukan secara bertahap 2,5\% sampai dengan $15 \%$. Pencampuran tanah dan arang dilakukan secara merata. Penambahan dilakukan dengan penambahan larutan garam pada tanah kering dengan komposisi penambahan garam sebanyak $2,5 \%$ berat tanah atau setara 25 gram berat garam ditambah dengan 5\% air atau setara dengan berat 50 gram air. Penambahan dilakukan secara bertahap 2,5\% larutan garam sampai dengan 15\%. Pencampuran tanah dan larutan garam dilakukan secara merata.

\section{B. Desain Sistem}

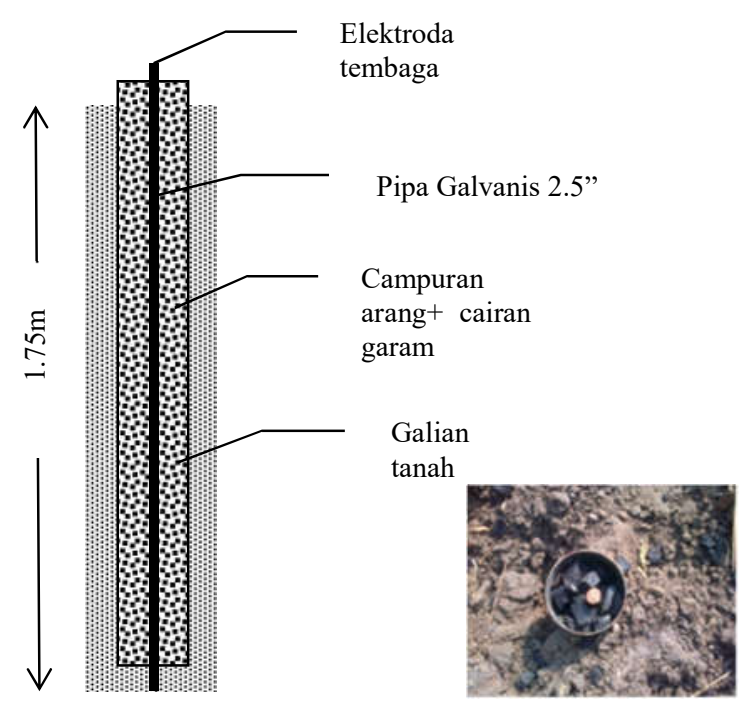

Gambar 1. Desain Sistem

1. Bahan Penelitian

Pengukuran meliputi 2 jenis kondisi tanah yaitu :

a. Kondisi tanah kapur; Pengukuran pada kondisi ini dilakukan di daerah Kecamatan Mantub, Lamongan .

b. Kondisi tanah padas (tanah pertanian); Pengukuran pada kondisi ini dilakukan di daerah Kecamatan Sarirejo, lamongan.

\section{Elektroda}

Elektroda yang digunakan pada pengukuran terbuat dari tembaga dengan diameter $1,5 \mathrm{~cm}$ yang dipasang vertikal atau ditanam di tanah padas dan kapur.

\section{Peralatan Pengukuran}

Peralatan-peralatan yang diperlukan dalam proses pengukuran tahanan pentanahan adalah Earth Resistance Tester.

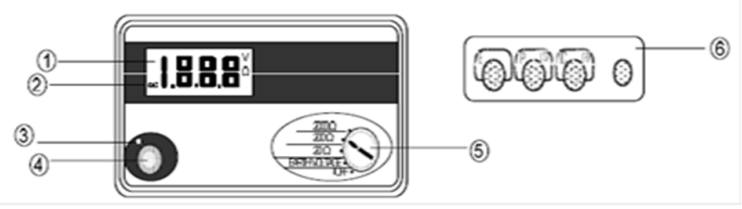

Gambar 2. Digital Earth Resistance Tester 
4. Sistem Pengukuran

Diagram rangkaian pengukuran seperti yang terlihat pada Gambar 3.

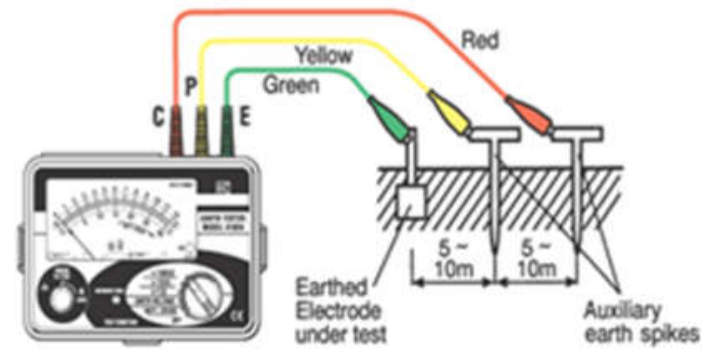

Gambar 3. Diagram rangkaian pengukuran elektroda tunggal

5. Langkah-langkah Pengukuran

a. Mempersiapkan peralatan dan bahan.

b. Mengecek tegangan baterai dengan menghidupkan Digital Earth Resistance Tester. Jika layar tampak bersih tanpa simbol baterai lemah berarti kondisi baterai dalam keadaan baik. Jika layar menunjukkan simbol baterai lemah atau bahkan layar dalam keadaan gelap berarti baterai pelu diganti.

c. Membuat rangkaian pengujian seperti pada Gambar 3 dengan menanam elektroda utama dan elektroda bantu. Menanam elektroda dengan memukul kepala elektroda menggunakan martil, jika menjumpai lapisan tanah yang keras sebaiknya jangan memaksakan penanaman elektroda.

d. Menetukan jarak antar elektroda bantu minimal 5 meter dan maksimal 10 meter.

e. Mengukur tegangan tanah dengan dengan mengarahkan range switch ke earth voltage dan pastikan bahwa nilai indikator $10 \mathrm{~V}$ atau kurang. Jika earth voltage bernilai lebih tinggi dari $10 \mathrm{~V}$ diperkirakan akan terjadi banyak kesalahan dalam nilai pengukuran tahanan.

f. Mengecek penghubung atau penjepit pada elektroda utama dan elektroda bantu dengan mensetting range switch ke 2000 $\Omega$ dan tekan tombol "Press To Test". Jika tahanan elektroda utama terlalu tinggi atau menunjukkan simbol "..." yang berkedip-kedip maka perlu dicek penghubung atau penjepit pada elektroda utama. g. Melakukan pengukuran. Mensetting range switch ke posisi yang diinginkan dan tekan tombol " Press To Test" selama beberapa detik.

h. Mencatat nilai ukur tahanan yang muncul dari Digital Earth Resistance Tester.

i. Mengembalikan posisi tombol " Press To Test" ke posisi awal.

j. Melakuan pengujian tahanan untuk kedalaman elektroda utama yang berbeda dengan langkah 3, 7, 8, 9. Tahapan yang sama untuk kondisi tanah yang berbeda.

\section{Pengukuran Tahanan Jenis Tanah}

Pengukuran tahanan jenis tanah biasanya dilakukan dengan cara:

1. Metode dua elektroda (two electroda method) atau

2. Metoda tiga titik (three pint method)

Arus yang masuk ke tanah mengalir secara radial dari elektroda, misalkan arah arus dalam tanah dari elektroda 1 ke elektroda 2 berbentuk permukaan bola dengan jari-jari r, luas permukaan tersebut adalah $2 \pi r^{2}$, dan rapat arus radial pada jarak r adalah $J=I / 2 \pi r^{2}$.

Bila $\rho$ adalah tahanan jenis tanah, maka kuat medan dalam tanah pada arah radial dengan jarak r adalah $E(r)=J$.

Jadi,

$$
E(r)=\frac{I \rho}{2 \pi r^{2}}
$$

Potensial pada jarak $r$ dari elektroda adalah integral dari gaya listrik dari jarak $r$ ke titik tak terhingga:

$$
V=\int_{r}^{\tilde{S}} E(r) d r=\frac{I \rho}{2 \pi r}
$$

Perbandingan antara tegangan dan arus atau tahan menjadi:

$$
R=\frac{\rho}{2 \pi r}
$$

Jadi,

Dari Gambar 4, terlihat, $r_{13}=r_{34}=r_{24}=a$.

$$
\begin{gathered}
V_{3}=\frac{I \rho}{2 \pi}\left(\frac{1}{a}-\frac{1}{2 a}\right) \\
V_{4}=\frac{I \rho}{2 \pi}\left(\frac{1}{2 a}-\frac{1}{a}\right)
\end{gathered}
$$


Beda tegangan antara titik 3 dan 4 adalah:

$$
\begin{aligned}
V_{34} & =\frac{I \rho}{2 \pi}\left(\frac{1}{a}-\frac{1}{2 a}+\frac{1}{2 a}+\frac{1}{a}\right) \\
& =\frac{I \rho}{2 \pi a}
\end{aligned}
$$

dan $\quad R_{34}=\frac{V_{34}}{I}=\frac{\rho}{2 \pi a}$

Jadi,

$$
\rho=2 \pi a R_{34}
$$

Bila $a$ dalam meter dan $\mathrm{R}$ dalam Ohm maka tahanan jenis dalam Ohm-meter. Dengan alat ukur yang dibuat khusus untuk ini yang terdiri dari generator yang diputar dengan tangan dan ohm-meter, dapat dibaca langsung tahanan antara elektroda arus dan elektroda tegangan.

Metoda tiga titik (three-point method) dimaksudkan untuk mengukur tahanan pengetanahan. Misalkan tiga buah batang pengetanahan di mana batang 1 yang tahanannya hendak diukur dan batang-batang 2 dan 3 sebagai batang pengetanahan pembantu yang juga belum diketahui tahanannya, seperti yang terlihat pada Gambar 4.

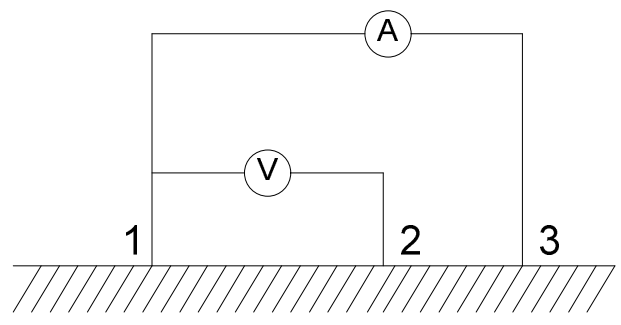

Gambar 4. Metode tiga titik

Bila tahanan di antara tiap-tiap titik batang pengetanahan diukur dengan arus konstan, tiap pengukuran dapat ditulis sebagai berikut:

$$
\begin{gathered}
R_{1 \_2}=\frac{V_{1 \_}}{I}=R_{11}+R_{22}-2 R_{12} \\
R_{1 \_3}=\frac{V_{1 \_} 3}{I}=R_{11}+R_{33}-2 R_{13} \\
R_{2 \_3}=\frac{V_{2 \_3}}{I}=R_{22}+R_{33}-2 R_{23} \\
\frac{V_{1 \_2}+V_{1 \_3}+V_{2 \_3}}{I}=2 R_{11}-2 R_{12}-2 R_{13}+2 R_{23}
\end{gathered}
$$

Tetapi, $\quad V_{1 \_3}=V_{1 \_2}+V_{2 \_3}$

Jadi, $\quad R=\frac{V_{1 \_2}}{I}=R_{11}-R_{12}-R_{13}+R_{23}$
Akhirnya,

$$
R_{11}=R+R_{12}+R_{13}-R_{23}
$$

Tahanan batang pengetanahan dari elektroda 1 diberikan oleh Persamaan (10) jika kita dapat membuat:

$$
R_{12}+R_{13}-R_{23}=0
$$

Keadaan ini dapat diperoleh dengan mengatur posisi elektroda 2 sehingga harga Persamaan (11) dipenuhi.

\section{HASIL DAN PEMBAHASAN}

Berikut merupakan hasil dari penelitian, perancangan dan pembuatan desain SIGARANG.

\section{A. Proses Kerja Sistem Grounding Arang dan Garam (SIGARANG)}

Sistem grounding arang dan dan garam bekerja berdasarkan penambahan air, arang dan garam. Berikut merupakan hasil dari penelitian, perancangan dan pembuatan desain SIGARANG untuk menentukan nilai resistansi pada tanah kapur dan padas. Berikut ini tabel hasil pengukuran megger pada tanah padas kondisi basah selama 30 hari.

Tabel 1. Hasil ukur tahanan isolasi tanah padas

\begin{tabular}{cccccc}
\hline No & Hari & $\begin{array}{c}\text { Nilai } \\
\text { Tahanan } \\
(\boldsymbol{\Omega})\end{array}$ & No & Hari & $\begin{array}{c}\text { Nilai } \\
\text { Tahanan } \\
(\boldsymbol{\Omega})\end{array}$ \\
\hline 1 & Minggu & 2 & 16 & Senin & 1,5 \\
\hline 2 & Senin & 2 & 17 & Selasa & 1,5 \\
\hline 3 & Selasa & 2 & 18 & Rabu & 1,5 \\
\hline 4 & Rabu & 2 & 19 & Kamis & 1,2 \\
\hline 5 & Kamis & 2 & 20 & Jum'at & 1,2 \\
\hline 6 & Jum'at & 2 & 21 & Sabtu & 1,2 \\
\hline 7 & Sabtu & 1,9 & 22 & Minggu & 1,2 \\
\hline 8 & Minggu & 1,9 & 23 & Senin & 1,2 \\
\hline 9 & Senin & 1,9 & 24 & Selasa & 1,2 \\
\hline 10 & Selasa & 1,9 & 25 & Rabu & 1,1 \\
\hline 11 & Rabu & 1,9 & 26 & Kamis & 1,1 \\
\hline 12 & Kamis & 1,9 & 27 & Jum'at & 1 \\
\hline 13 & Jum'at & 1,5 & 28 & Sabtu & 1 \\
\hline 14 & Sabtu & 1,5 & 29 & Minggu & 1 \\
\hline 15 & Minggu & 1,5 & 30 & Senin & 1 \\
\hline
\end{tabular}

\section{Keterangan :}

a. Penambahan $525 \mathrm{~g}$ garam +3 liter air dan arang menunjukan nilai resistansi $2 \mathrm{ohm}$.

b. Penambahan $875 \mathrm{~g}$ garam +5 liter air dan arang menunjukan nilai resistansi $1,9 \mathrm{ohm}$.

c. Penambahan $1750 \mathrm{~g}$ garam +5 liter air dan arang menunjukkan nilai resistansi $1,5 \mathrm{ohm}$. 
d. Penambahan 2625 g garam +5 liter air dan arang menunjukkan nilai resistansi $1,2 \mathrm{ohm}$.

e. Penambahan $3150 \mathrm{~g}$ garam +6 liter air dan arang menunjukkan nilai resistansi $1,1 \mathrm{ohm}$.

f. Penambahan 3500 g garam +6 liter air dan arang menunjukkan nilai resistansi $1 \mathrm{ohm}$.

Rata-rata nilai resistansi pentanahan pada tabel 1 kondisi tanah basah 1,52 $\Omega$.

Hasil pengukuran megger pada tanah padas kondisi kering selama 30 hari dapat dilihat pada Tabel 2 berikut :

Tabel 2. Kondisi tanah padas kondisi kering

\begin{tabular}{cccccc}
\hline No & Hari & $\begin{array}{c}\text { Nilai } \\
\text { Tahanan } \\
(\boldsymbol{\Omega})\end{array}$ & No & Hari & $\begin{array}{c}\text { Nilai } \\
\text { Tahanan } \\
(\boldsymbol{\Omega})\end{array}$ \\
\hline 1 & Minggu & 2,5 & 16 & Senin & 2 \\
\hline 2 & Senin & 2,5 & 17 & Selasa & 2 \\
\hline 3 & Selasa & 2,5 & 18 & Rabu & 2 \\
\hline 4 & Rabu & 2,5 & 19 & Kamis & 1,5 \\
\hline 5 & Kamis & 2,5 & 20 & Jum'at & 1,5 \\
\hline 6 & Jum'at & 2,5 & 21 & Sabtu & 1,5 \\
\hline 7 & Sabtu & 2 & 22 & Minggu & 1,5 \\
\hline 8 & Minggu & 2 & 23 & Senin & 1,5 \\
\hline 9 & Senin & 2 & 24 & Selasa & 1,5 \\
\hline 10 & Selasa & 2 & 25 & Rabu & 1,1 \\
\hline 11 & Rabu & 2 & 26 & Kamis & 1,1 \\
\hline 12 & Kamis & 2 & 27 & Jum'at & 1,1 \\
\hline 13 & Jum'at & 2 & 28 & Sabtu & 1,1 \\
\hline 14 & Sabtu & 2 & 29 & Minggu & 1,1 \\
\hline 15 & Minggu & 2 & 30 & Senin & 1,1 \\
\hline
\end{tabular}

\section{Keterangan :}

a. Penambahan $875 \mathrm{~g}$ garam +3 liter air dan arang menunjukan nilai resistansi $2,5 \mathrm{ohm}$

b. Penambahan $1750 \mathrm{~g}$ garam +3 liter air dan arang menunjukan nilai resistansi $2 \mathrm{ohm}$

c. Penambahan $3150 \mathrm{~g}$ garam +3 liter air dan arang menunjukan nilai resistansi $1,5 \mathrm{ohm}$

d. Penambahan $3500 \mathrm{~g}$ garam + 6liter air dan arang menunjukan nilai resistansi $1,1 \mathrm{ohm}$

Rata-rata nilai resistansi pentanahan pada Tabel 2 kondisi tanah kering 1,82 $\Omega$.

Hasil pengukuran megger pada kondisi tanah kapur kondisi basah dapat dilihat pada Tabel 3 berikut:

Tabel 3. Hasil nilai tahanan isolasi tanah kondisi tanah kapur

\begin{tabular}{cccccc} 
No & Hari & $\begin{array}{c}\text { Nilai } \\
\text { Tahanan } \\
(\Omega)\end{array}$ & No & Hari & $\begin{array}{c}\text { Nilai } \\
\text { Tahanan } \\
(\Omega)\end{array}$ \\
\hline 1 & Minggu & 3 & 9 & Senin & 2,5 \\
\hline 2 & Senin & 3 & 10 & Selasa & 2 \\
\hline 3 & Selasa & 3 & 11 & Rabu & 2 \\
\hline 4 & Rabu & 3 & 12 & Kamis & 2 \\
\hline 5 & Kamis & 2,5 & 13 & Jum'at & 2 \\
\hline 6 & Jum'at & 2,5 & 14 & Sabtu & 2 \\
\hline 7 & Sabtu & 2,5 & 15 & Minggu & 2 \\
\hline 8 & Minggu & 2,5 & & & \\
\hline
\end{tabular}

\section{Keterangan :}

a. Penambahan $875 \mathrm{~g}$ garam +3 liter air dan arang menunjukan nilai resistansi $3 \mathrm{ohm}$.

b. Penambahan $1750 \mathrm{~g}$ garam +3 liter air dan arang menunjukan nilai resistansi $2,5 \mathrm{ohm}$.

c. Penambahan 3500 g garam +3 liter air dan arang menunjukan nilai resistansi $2 \mathrm{ohm}$.

Rata-rata nilai resistansi pentanahan pada Tabel 3 kondisi tanah basah $2,43 \Omega$.

Hasil pengukuran megger pada tanah kapur kondisi kering sebagai berikut:

Tabel 4. Nilai tahanan tanah pada Kondisi Tanah Kapur

\begin{tabular}{ccc}
\hline No & Hari & $\begin{array}{c}\text { Nilai Tahanan } \\
(\boldsymbol{\Omega})\end{array}$ \\
\hline 1 & Minggu & 3,5 \\
\hline 2 & Senin & 3,5 \\
\hline 3 & Selasa & 3,5 \\
\hline 4 & Rabu & 3,5 \\
\hline 5 & Kamis & 3,5 \\
\hline 6 & Jum'at & 3 \\
\hline 7 & Sabtu & 3 \\
\hline 8 & Minggu & 3 \\
\hline 9 & Senin & 3 \\
\hline 10 & Selasa & 3 \\
\hline 11 & Rabu & 2,5 \\
\hline 12 & Kamis & 2,5 \\
\hline 13 & Jum'at & 2,5 \\
\hline 14 & Sabtu & 2,5 \\
\hline 15 & Minggu & 2,5 \\
\hline
\end{tabular}

\section{Keterangan :}

a. Penambahan $875 \mathrm{~g}$ garam + 3liter air dan arang menunjukan nilai resentasi 3,5ohm.

b. Penambahan $1750 \mathrm{~g}$ garam +3 liter air dan arang menunjukan nilai resentasi $3 \mathrm{ohm}$.

c. Penambahan $3500 \mathrm{~g}$ garam +3 liter air dan arang menunjukan nilai resentasi 2,5ohm.

Rata-rata nilai resistansi pentanahan pada Tabel 4 kondisi tanah basah $3 \Omega$.

B. Hasil Perbandingan Batang Pentanahan (Ground Rod) Secara Umum dan SIGARANG

Tabel 5. Perbandingan SIGARANG dan non SIGARANG

\begin{tabular}{lcccc}
\hline \multirow{2}{*}{$\begin{array}{c}\text { Jenis } \\
\text { pentanahan }\end{array}$} & \multicolumn{2}{c}{ Tana Padas } & \multicolumn{2}{c}{ Tanah Kapur } \\
\cline { 2 - 5 } & kering & basah & Kering & Basah \\
\hline $\begin{array}{l}\text { Batang } \\
\text { pentanahan } \\
\text { secara umum }\end{array}$ & $3 \Omega$ & $2,5 \Omega$ & $3,8 \Omega$ & $3,5 \Omega$ \\
\hline $\begin{array}{l}\text { Sistem } \\
\text { SIGARANG }\end{array}$ & $1,1 \Omega$ & $1 \Omega$ & $2,5 \Omega$ & $2 \Omega$ \\
\hline
\end{tabular}




\section{Pembahasan}

Tahanan jenis tanah berdasarkan jenis tanah pada PUIL 2000 dapat dilihat pada Tabel 6 berikut:

Tabel 5. Tahanan Jenis Tanah

\begin{tabular}{lc}
\hline \multicolumn{1}{c}{ Jenis Tanah } & Tahanan Jenis $(\mathbf{\Omega}-\mathbf{m})$ \\
\hline Tanah Rawa & 30 \\
\hline Tanah Liat dan Tanah Ladang & 100 \\
\hline Pasir Basah & 200 \\
\hline Kerikil basah & 500 \\
\hline Pasir dan kerikil kering & 1000 \\
\hline Tanah Berbatu & 3000 \\
\hline & (sumber: PUIL 2000)
\end{tabular}

Dari hasil pengamatan, resistansi tanah berdasakan PUIL 2000, dapat dibandingkan jika tanah kondisi basah $\rho 200 \Omega$, jika diambil tahanan $200 \mathrm{ohm}$ dan nilai rata- rata $1,52 \Omega$.

$\mathrm{R}$ tanah $\rho=2 \pi a R$

$$
\begin{aligned}
& =2.22 / 7 \times 10 \times 1,52 \\
& =440 \times 1,52 / 7=95,5 \text { ohm meter }
\end{aligned}
$$

Resistansi tanah pada tanah padas basah $95,5 \Omega$.

Dari hasil pengamatan, resistansi tanah berdasakan PUIL 2000, dapat dibandingkan jika tanah kondisi basah $\rho 200 \Omega$, jika diambil tahanan $200 \mathrm{ohm}$ dan nilai rata- rata $1,82 \Omega$.

$\mathrm{R}$ tanah $\rho=2 \pi a R$

$$
\begin{aligned}
& =2.22 / 7 \times 10 \times 1,82 \\
& =440 \times 1,82 / 7=114,4 \mathrm{ohm} \text { meter }
\end{aligned}
$$

Resistansi tanah pada tanah padas kering $114,4 \Omega$.

Dari hasil pengamatan, resistansi tanah berdasakan PUIL 2000, dapat dibandingkan jika tanah kondisi basah $\rho 200 \Omega$, jika diambil tahanan $200 \mathrm{ohm}$ dan nilai rata- rata $3 \Omega$.

$\mathrm{R}$ tanah $\rho=2 \pi a R$

$$
\begin{aligned}
& =2.22 / 7 \times 10 \times 3 \\
& =440 \times 3 / 7=188,5 \text { ohm meter }
\end{aligned}
$$

Resentasi tanah pada tanah kapur kering $188,5 \Omega$.

Penambahan air, arang dan garam dapat memperkecil nilai resistansi pada tanah. Nilai resistansi pembumian dengan penambahan air, arang dan garam menjadi lebih kecil dibandingan sebelum penambahan air, arang dan garam.

\section{KESIMPULAN}

Berdasarkan hasil pengujian dan pembahasan dapat ditarik simpulan sebagai berikut:

1. Berdasarkan hasil penelitian disimpulkan bahwa pentanahan air, garam dan arang dengan ukuran 5:2:1 menghasilkan rata-rata nilai tahanan $1,52 \Omega$ pada tanah padas kondisi tanah basah pada tabel 4.1, dan ratarata $2,43 \Omega$ pada tanah kapur kondisi basah pada tabel 4.3. dibandingkan dengan metode tanpa Sigarang pentanahan nilai rata- rata pada tanah padas $3 \Omega$ dan pada tanah kapur 3,5 $\Omega$.

2. Pentanahan menggunakan air, garam dan arang (SIGARANG) dapat menghasilkan efisiensi pentanahan sebesar $75 \%$ pada tanah kapur. Dan efisiensi pentanahan pada tanah padas rata- rata $65 \%$ dibandingkan pentanahan tanpa sigarang.

\section{DAFTAR PUSTAKA}

[1]. Munandar, A. A., Kawahara, S. (1979). Teknik Tenaga Listrik II : Transmisi Distribusi. Pradnya Paramita, Jakarta.

[2]. Hutahuruk, T.S. (1987). Pengetanahan Netral Sistem Tenaga dan Pengetanahan Peralatan. Penerbit Erlangga, Jakarta.

[3]. , Persyaratan Umum Instalasi Listrik 2000 (PUIL 2000). Badan Standarisasi Nasional, Jakarta. 